\title{
On the mechanisms of nucleation and subsequent development of the PLC bands in an AlMg alloy
}

\author{
D. Yuzbekova, A. Mogucheva*, Yu. Borisova, R. Kaibyshev \\ Belgorod State University, Pobedy 85, 308015 Belgorod, Russia
}

\section{A R T I C L E I N F O}

\section{Article history:}

Received 14 December 2020

Received in revised form 6 February 2021

Accepted 8 February 2021

Available online 11 February 2021

\section{Keywords:}

Metals and alloys

Microstructures

Mechanical properties

Portevin-Le Chatelier effect

\begin{abstract}
A B S T R A C T
The nucleation and subsequent development of the Portevin-Le Chatelier bands during tensile deformation in a binary AlMg alloy was investigated by the digital image correlation technique. The following states of the material were employed for the current investigation: coarse-grained (CG), fine-grained (FG) after equal channel angular pressing (ECAP), severely strained (SS) after ECAP followed by cold rolling. Special attention was paid to the nucleation of an embryo band by maximizing the contrast of the deformation images. Particular spatiotemporal patterns of the alloy in three different conditions, testifying to the initiation of an embryo band having a wedge shape on the lateral surface of the specimen, were obtained at high and intermediate strain rates. The evaluation of the serration amplitude and the band velocity showed that the dependence of these values on strain consists of two stages (the linear growth-up/drop stage and the steady-state stage) for CG materials and only one stage (the linear growth-up/drop stage) for FG materials. The nucleation of deformation bands always occurs according to a mixed mechanism, in which the thickening of the embryo slows down with a decrease in the strain rate.
\end{abstract}

(c) 2021 Elsevier B.V. All rights reserved.

\section{Introduction}

The phenomenon of plastic instability in alloys, known as the Portevin-Le Chatelier (PLC) effect is manifested in strain localizations in the form of deformation bands resulting in repeated serrations on the stress-strain curves [1-3]. Numerous studies in this field have led to significant progress in understanding the PLC effect [4-11]. The PLC mechanism is normally associated with dynamic strain aging (DSA), i.e., pinning of dislocations by impurity atoms and alloying solutes during deformation, while dislocations are blocked on obstacles [12-15]. A number of studies were devoted to the classification of the PLC effect into three major types: according to the jerky flow of the deformation curve [16,17], according to the regularities in distribution of the stress oscillation magnitudes $[18,19]$, and according to the behavior of the deformation bands [20-22]. Type A behavior is characterized by an increase in the flow stress followed by a drop to or below the general stress level and a repetitive continuous propagation of deformation bands. Asymmetrical monotonically decreasing distributions of stress drops correspond to type A. Serrations occurring near the general level of the stress-strain curve is attributed to the type B behavior. The hopping

\footnotetext{
* Corresponding author.

E-mail address: annamoguch@gmail.com (A. Mogucheva).
}

or relay-race propagation of PLC bands is typical for serrations of this type. Type B is characterized by an asymmetrical distribution of peaks with a maximum shifted to the range of small stress drops. Type $C$ serrations, which are characterized by large stress drops below the general stress level, are associated with the short-term occurrence of immobile deformation bands that nucleate virtually randomly along the tensile axis. The peak-shaped distribution is characteristic of type $C$ stress drops.

Two types of the PLC band nucleation and its subsequent development were identified $[23,24]$. The first scenario is related to the nucleation of a relatively large embryo band on the lateral surface of the specimen, followed by transversal development into the volume at an angle with relation to the tensile axis. The second scenario is related to the initiation of an embryo band with a thickness of several atomic planes over the entire cross-section, and its growth in the tensile direction. This thin band then grows until its thickening is arrested by a stress drop. Moreover, a possible manifestation of mixed scenarios may be when the band appears on the side surface and then expands in the tensile direction during growth into the volume at an angle with relation to the tensile axis. Thus, the embryo acquires a wedge shape. It should be noted that various attempts to associate scenarios of band development with different types of PLC bands do not agree with each other $[23,25]$. Thus, the mechanism of nucleation of the PLC band has not been studied in sufficient detail and requires further investigation. 
The great potential for the application of ultra-fine grained (UFG) materials has aroused interest in studying the PLC effect in UFG alloys. Recent studies have shown the effect of grain refinement on various aspects of the manifestation of plastic flow instability in model Al-Mg alloys [2,26-31]. However, the influence of the microstructure on the nucleation of the deformation bands has not been clarified.

The present work is focused on the influence of the microstructure on the nucleation and subsequent development of type B deformation bands at intermediate strain rates in a "model" $\mathrm{Al}-\mathrm{Mg}$ alloy. It was previously reported that an independent determination of the strain rate scale for each frame, providing maximum contrast of images, was successfully used for better identification of the nucleation of an embryo [32]. With this in mind, the deformed images were obtained by maximizing the contrast in the present study. The nucleation and subsequent development of bands characteristic of high (type A) and intermediate (type B) strain rates in an $\mathrm{Al}-\mathrm{Mg}$ alloy with different microstructures were comparatively analyzed.

\section{Material and experimental procedure}

An Al-Mg alloy with the chemical composition of $\mathrm{Al}-3 \mathrm{Mg}$ (wt\%) was used in this study. This alloy may also contain small amounts of such elements as Fe, Si, and $\mathrm{Zn}$. This material was cast by the semicontinuous processing method. The ingots were then heated to $500{ }^{\circ} \mathrm{C}$ and kept at this temperature for $4 \mathrm{~h}$, and then furnace-cooled to room temperature. Then, using different thermomechanical processing (TMP), three different microstructures were obtained:

(1) Rolling and subsequent annealing were used to achieve a recrystallized microstructure (hereafter, the coarse-grained (CG) alloy). The average grain size of almost equiaxed coarse grains was $40 \mu \mathrm{m}$; and the lattice dislocation density was $1.0 \times 10^{13} \mathrm{~m}^{-2}$.

(2) Equal channel angular pressing (ECAP) was utilized to obtain a fine-grained microstructure (hereafter, the fine-grained (FG) alloy). The average grain size was $2 \mu \mathrm{m}$; and the dislocation density was $1.5 \times 10^{14} \mathrm{~m}^{-2}$.

(3) The ECAP samples were additionally cold rolled (CR) to obtain a severely strained (SS) condition. This TMP has almost no effects on the grain size distribution and provides a very high dislocation density of the lattice $\left(\rho=2.7 \times 10^{14} \mathrm{~m}^{-2}\right)$.

Other details of materials and processing were described previously [27]. Tensile tests were carried out with initial strain rates of $3 \times 10^{-5} \mathrm{~s}^{-1}$ and $1.4 \times 10^{-4} \mathrm{~s}^{-1}$ at room temperature on a Zwick 1476 testing machine. Tensile specimens with a gauge length of $35 \mathrm{~mm}$ and a cross section of $3 \times 7 \mathrm{~mm}^{2}$ were cut parallel to the last extrusion axis of the pressed billets and/or the rolling direction of the sheets. Three samples were tested for each set of conditions.

The PLC bands were detected using a digital image correlation (DIC) process. Deformed images with a spatial resolution of about 25 pixels $/ \mathrm{mm}$ were captured at a rate of 15 frames/s. Other details of the DIC method were described in an earlier publication [27]. The Vic-2D correlation software was employed for the calculations (details of this method can be seen elsewhere [33]). The behavior of the PLC band in some CG specimens was studied by the DIC method on two orthogonal surfaces of the specimen simultaneously.

\section{Results and discussion}

\subsection{Correlation between microstructure and deformation behavior}

Typical engineering stress-strain curves for strain rates of $1.4 \times 10^{-4} \mathrm{~s}^{-1}$ and $3 \times 10^{-5} \mathrm{~s}^{-1}$ and CG, FG and SS conditions are shown in Fig. 1. The tensile curves of the CG alloy demonstrate a distinct strain hardening and have a general parabolic shape until necking $[26,34,35]$. The grain refinement by ECAP reduces the strain hardening. Thus, the flow stress increases steadily from the yield point to the necking point, similar to the CG alloy, however, the work hardening rate is much lower. After ECAP, ductility decreases in 1.5 times.

The deformation curves of the Al-Mg alloy in the CG and FG conditions exhibit the PLC instability caused by DSA [36,37]. Closeup of the regions marked by the rectangles in Fig. $1 \mathrm{a}$ and $\mathrm{b}$ show the behavior of the serrated flow in more detail. The serrations appearing in the packets, typical of type $B$ serrations, can be seen on the deformation curves of the CG material at $3 \times 10^{-5} \mathrm{~s}^{-1}$ and $1.4 \times 10^{-4} \mathrm{~s}^{-1}$ and with maximum amplitudes of $5.5 \mathrm{MPa}$ and $6.2 \mathrm{MPa}$, respectively (Fig. 1a). The grain refinement by ECAP leads to an increase in the stress serration amplitudes. The maximum amplitudes reach $11 \mathrm{MPa}$ and $13.9 \mathrm{MPa}$ at $3 \times 10^{-5} \mathrm{~s}^{-1}$ and $1.4 \times 10^{-4} \mathrm{~s}^{-1}$, respectively (Fig. 1b). The deformation curves of the FG alloy at both strain rates display a portion with small serrations, which allows us to suggest that the large serrations occurring before and after this portion are below the general level of the $\sigma-\varepsilon$ curve. Besides, Fig. $1 \mathrm{~b}$ reveals that the typical behavior of type $B$ serrations appearing in the packets is destroyed after ECAP. The overall behavior of the FG alloy makes one think about a mixture of types B and C.

The symbols on the curves shown in Fig. $1 \mathrm{a}$ and $\mathrm{b}$ indicate variations of the serration amplitudes depending on the strain for the $\mathrm{Al}-3 \% \mathrm{Mg}$ alloy in CG and FG conditions, respectively. The serration amplitude for the CG conditions is clearly divided into two steps: the rapid linear growth up and the saturated plateau. The linear growth up occurs due to the enhanced interaction between solutes and mobile dislocations (known as DSA). On the saturated plateau, the effective ageing time for the solute diffusion process in the DSA may become saturated owing to the high density of obstacles. This results in the maximum concentration of the solute around the mobile dislocations and, consequently, in a fixed intensity of the DSA [33]. For the FG materials, only the linear growth up step was obtained.

The significant deviation of the increasing amplitude from the linearity in the FG material is probably due to the larger strained and less homogeneous FG microstructure after ECAP as compared to the CG material.

The rapid necking of the SS alloy occurs soon after the yielding onset (Fig. 1c). It should be noted that the deformation curve of the SS material may exhibit oscillations after the onset of necking $\left(1.4 \times 10^{-4} \mathrm{~s}^{-1}\right)$ or remain smooth $\left(3 \times 10^{-5} \mathrm{~s}^{-1}\right)$. The stress oscillations amplitude achieves a maximum of $10 \mathrm{MPa}$ after necking and appears below the envelope $\sigma-\varepsilon$ curve. Therefore, this can be tentatively ascribed to type C serrations as suggested in the previous work [27].

\subsection{Effect of microstructure on the PLC band behavior}

\subsubsection{Spatiotemporal aspects of PLC instabilities at intermediate strain rates}

Since the spatiotemporal behavior of the CG and FG alloys is practically the same at strain rates of $1.4 \times 10^{-4} \mathrm{~s}^{-1}$ and $3 \times 10^{-5} \mathrm{~s}^{-1}$, one strain rate was chosen for further detailed analysis of the features of the nucleation and subsequent development of the bands. The DIC technique was used to gain insight into the behavior of plastic strain at the macroscopic level. The scale of colors was defined separately for each frame, fixing on the maximum and minimum strain rate values. This approach allows visualization of the nucleation of an embryo due to the maximum contrast [32]. In Figs. 2-13, the maximum values of the local strain rate are indicated over each frame. The deformation curves recorded by the testing machine (red lines) and an external device coupled with the DIC system (black dots) were synchronized. Each black dot indicates the instant when a DIC image is taken. 

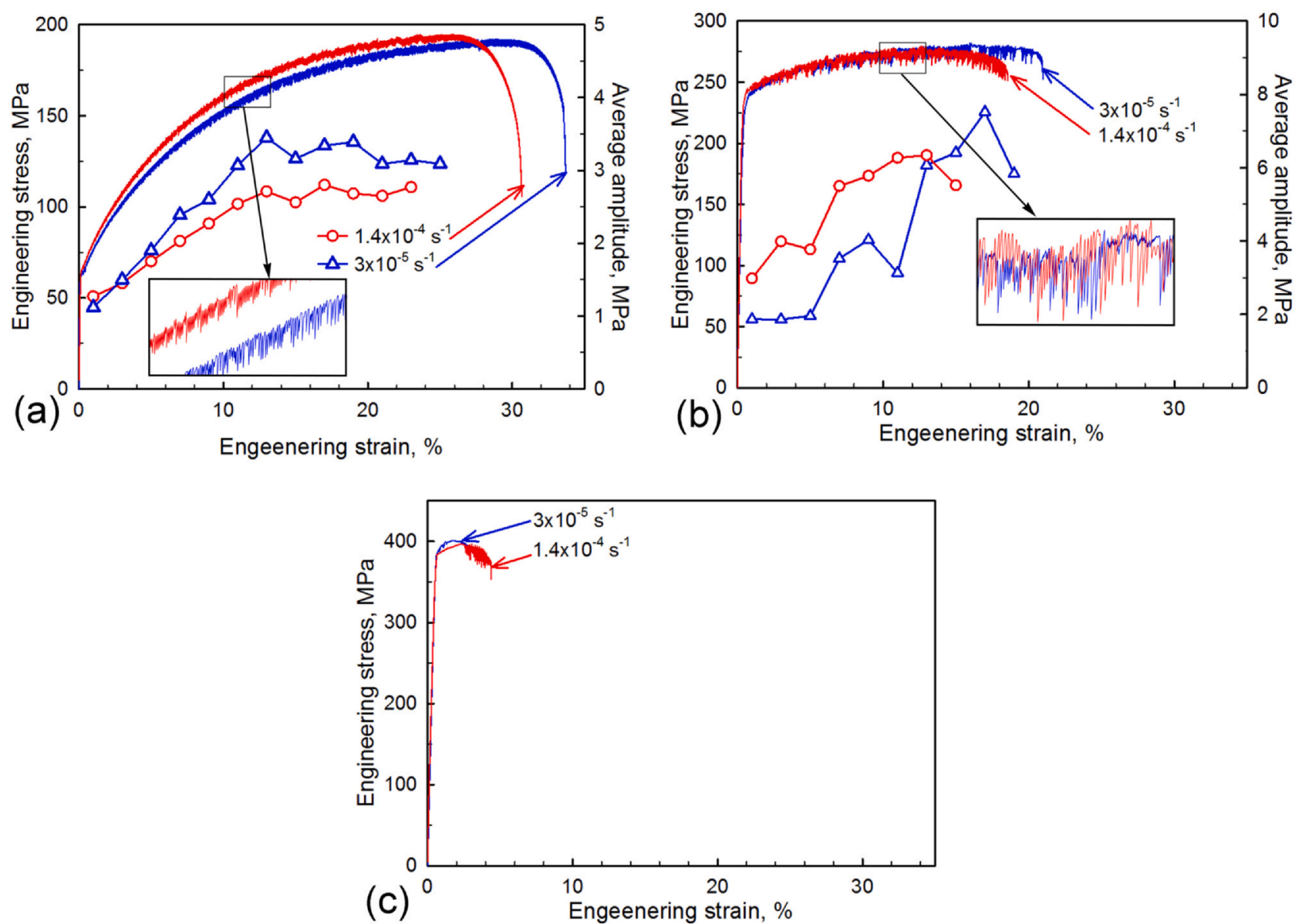

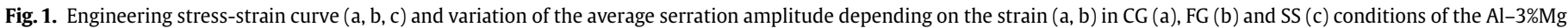
alloy deformed at strain rates of $1.4 \times 10^{-4} \mathrm{~s}^{-1}$ and $3 \times 10^{-5} \mathrm{~s}^{-1}$.

A series of DIC images and the corresponding regions of the stress versus time and frame number curve of the Al-3\% Mg alloy in the CG condition, tested at $1.4 \times 10^{-4} \mathrm{~s}^{-1}$, are presented in Figs. 2-4. Fig. 2b reveals two PLC bands at the instants corresponding to the first stress drop with an amplitude of $0.3 \mathrm{MPa}$ at the beginning of the yield plateau (frames 1-3) and the first stress drop with an amplitude above $1 \mathrm{MPa}$ at the end of the yield plateau (frames 4-6). The maximum local strain rate, $\dot{\varepsilon}_{l o c}$, is an order of magnitude higher than the applied strain rate, $\dot{\varepsilon}_{a}$, for both bands (s. frames 2 and 5 in Fig. $2 \mathrm{~b}$ ). For comparison, the maximum $\dot{\varepsilon}_{l o c}$ of the first band was only four times higher than $\dot{\varepsilon}_{a}$ for the Al-3\%Mg alloy in the CG condition tested at $5 \times 10^{-3} \mathrm{~s}^{-1}$ [27]. Frame 1 in Fig. $2 \mathrm{~b}$ illustrates the appearance of an embryo of the first band, where the quantitative relation between the local and applied strain rates is $\dot{\varepsilon}_{\text {loc }} \mid \dot{\varepsilon}_{a}>6$ for the band detection, whereas it is 3 times higher in the well-developed PLC band. Two features of the first band should be noted: the zone of the localized deformation is directed horizontally, and the position of the PLC band does not change. The band on frame 5 is inclined at approximately $60^{\circ}$ from the tensile axis. Frame 6 shows the diffuse band following the PLC band, which persists until the next stress drop. The occurrence and "healing" of weak diffuse bands were also detected during the yield plateau (not shown).
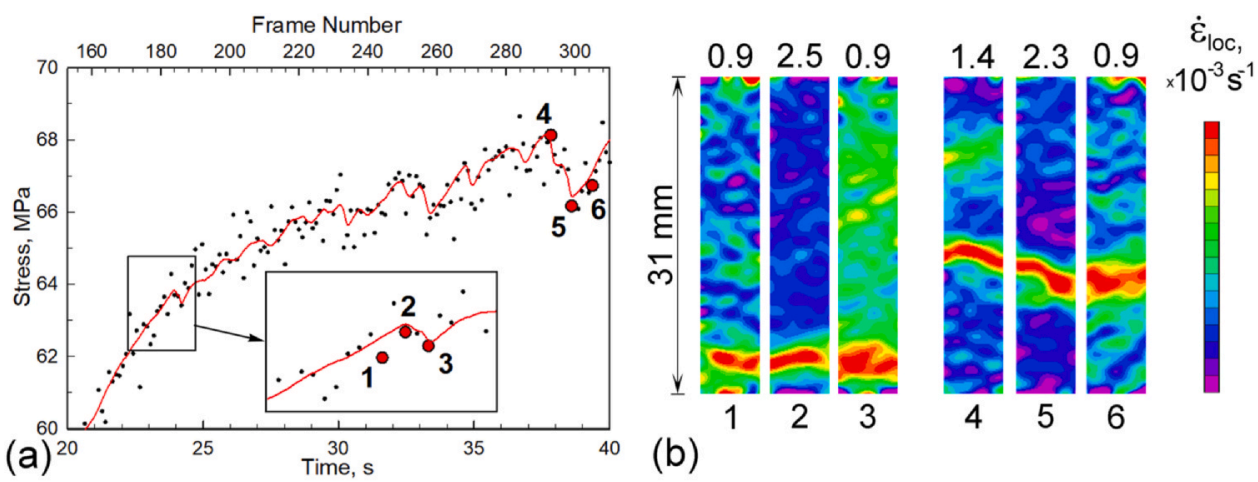

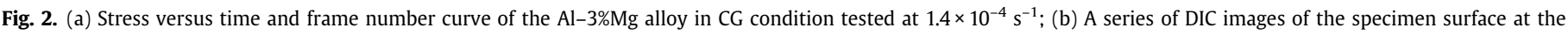

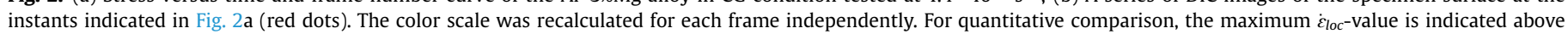
each frame. 

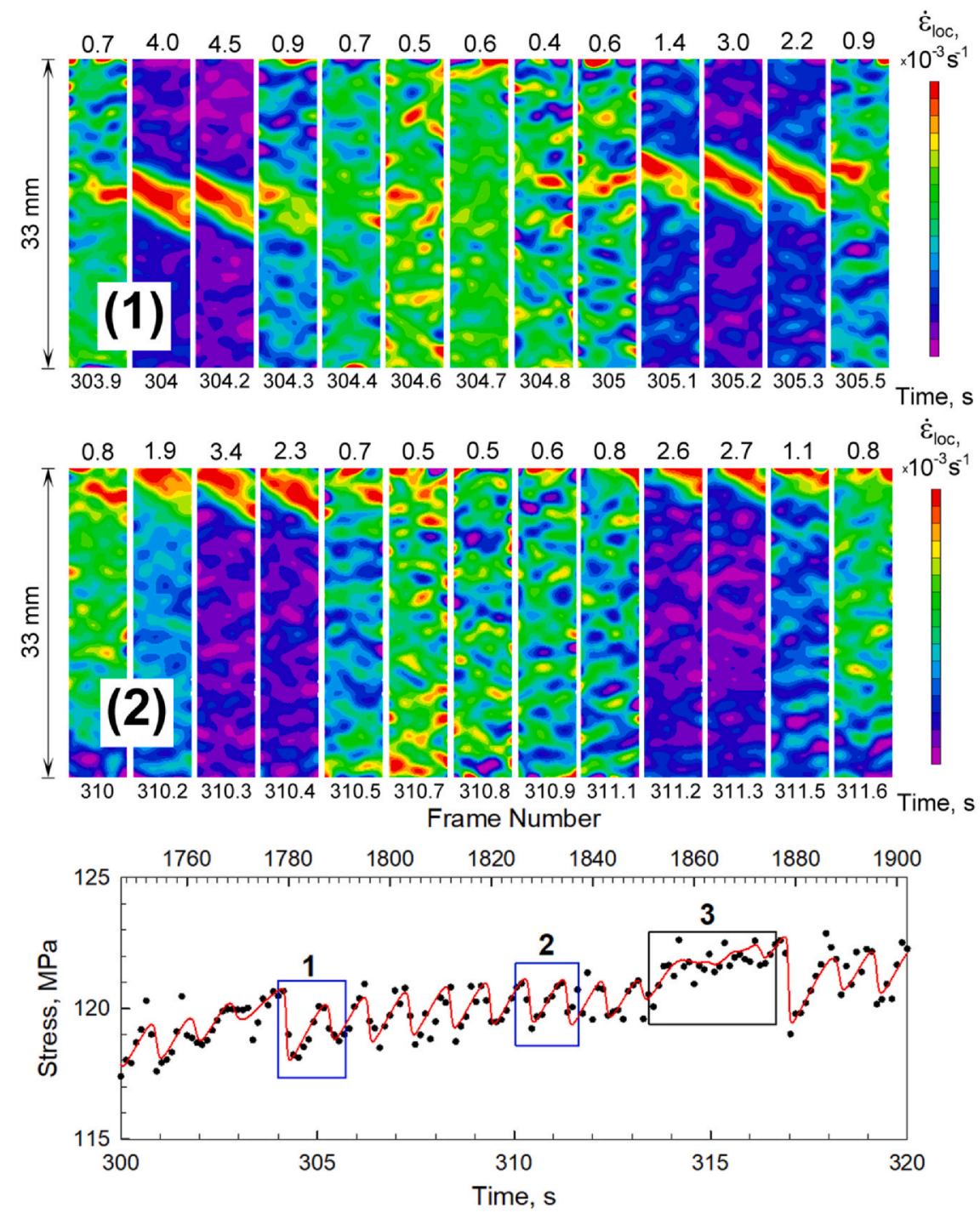

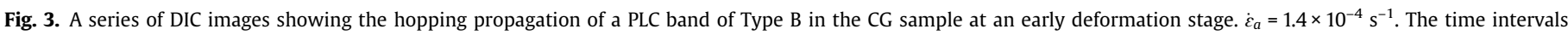
correspond to the blue rectangles in the bottom plot, which shows the instants on the stress-time curve when the images were taken.

Fig. 3 shows a typical series of consecutive PLC bands characterizing a hopping or relay-race propagation (Type B) for the CG material. Sometime later after the band vanishes, the next PLC band appears near to the previous band position, indicating a memory effect. The PLC bands are initiated in the middle gauge region of the specimen as shown for region 1 and propagate in a hopping manner to the upper edge of the specimen as shown for region 2 in Fig. 3. The stress oscillates for the indicated time interval practically continuously. The band lifetime includes the appearance of a completed band, sometimes its short-distance propagation, and disappearance, while the nucleation of an embryo is not implied. A completed band is a band that occupies the entire cross section of the sample, and its local strain rate is an order of magnitude higher than the applied strain rate. The frames observed at $t=\{304.0-304.2\} \mathrm{s}$ and $t=\{305.2-305.3\} \mathrm{s}$ exhibit the band lifetime for region 1 of the stress-time curve. As can be seen in Fig. 3, the band lifetime is one third of the band-free phase. In region 3 of the stress-time curve, the PLC bands are not observed, which is typical for type B [32]. The nucleation of an embryo can be seen on the frames obtained at $t=303.9 \mathrm{~s}$ and $t=305.1 \mathrm{~s}$. The ratio of $\dot{\varepsilon}_{l o c} \mid \dot{\varepsilon}_{a}$ for the embryo bands was 5 and 10 at $t=303.9 \mathrm{~s}$ and $\mathrm{t}=305.1 \mathrm{~s}$, respectively. It should be noted that it is difficult to judge the process of band formation if this process is recorded by only one frame.
Nevertheless, we still manage to fix the initial stage of the band growth. Some features of the band formation can be seen on the frames obtained at $t=303.9 \mathrm{~s}$ and $t=305.1 \mathrm{~s}$, due to the maximization of the image contrast. Namely, the embryo band does not cover the entire area of the PLC band, but only one of its sides indicating the initiation of the embryo band on the lateral surface of the specimen. This occurs because dislocation sources can be activated more readily at the edges of the sample than in the volume, and the propagation is controlled by the tendency to relax local overstresses by plastic deformation [38].

Fig. 4 shows a series of DIC images for the hopping propagation of the PLC band after a rather large deformation of the CG sample at $1.4 \times 10^{-4} \mathrm{~s}^{-1}$. The frames obtained in the time interval from $1215.9 \mathrm{~s}$ to $1217.6 \mathrm{~s}$ exhibit a band-free phase. Thus, it is obvious that the duration of the band-free phase increases with strain. The ratio of the band-free phase to the band lifetime becomes higher than 4.5 . It should be noted that the frames obtained at $1215.4 \mathrm{~s}$ and $1217.6 \mathrm{~s}$ display diffuse bands corresponding to stress drops and PLC band formations. It is interesting that the value of the maximum $\dot{\varepsilon}_{l o c}$ for frame obtained at $1215.5 \mathrm{~s}$ corresponds to the well-developed PLC band $\left(\dot{\varepsilon}_{l o c}=3.1 \times 10^{-3} \mathrm{~s}^{-1}\right)$, but the band does not cover the entire area of the specimen width and remains as the embryo band. This suggests that the ratio $\dot{\varepsilon}_{l o c} / \dot{\varepsilon}_{a}$ for the embryo band increases up to 20 with straining. 

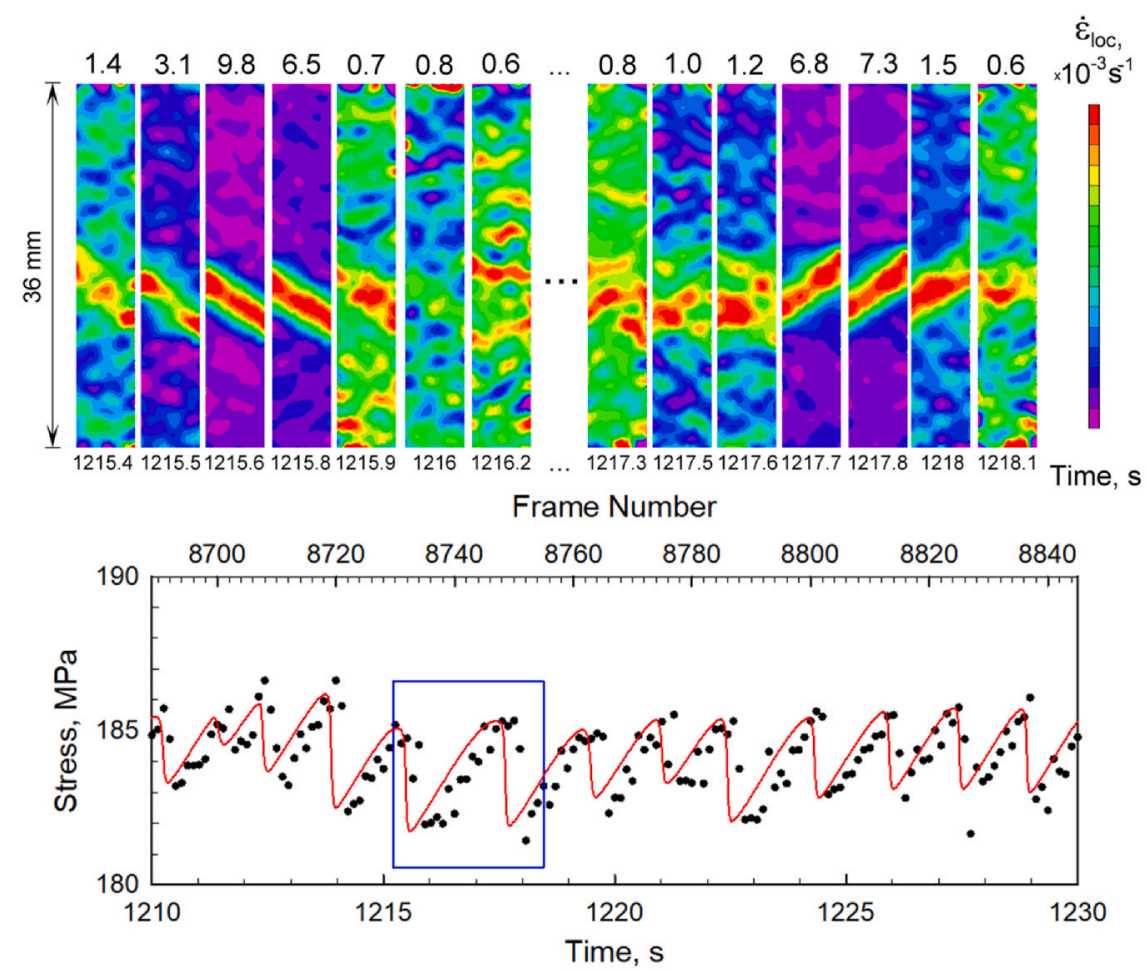

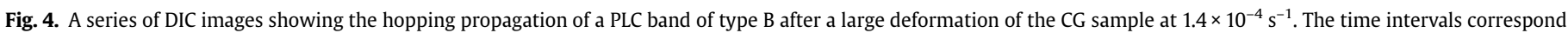
to the blue rectangle in the bottom plot, which shows the instants on the stress-time curve when the images were taken.

Figs. 5 and 6 display the experimental observation of PLC bands in the FG alloy deformed at a strain rate of $1.4 \times 10^{-4} \mathrm{~s}^{-1}$. The nucleation of the first band corresponds to the first large stress drop marked with the arrow in Fig. 5a. The maximum $\dot{\varepsilon}_{\text {loc }}$ for the first band in the FG conditions is $8.5 \times 10^{-3} \mathrm{~s}^{-1}$ (Fig. 5a), while in the CG state it is $2.5 \times 10^{-3} \mathrm{~s}^{-1}$. Thus, we can assume that the plastic deformation localization becomes more intense after the grain refinement. The embryo of the first band was fixed on a frame obtained at $t=49.3 \mathrm{~s}$, wherein the ratio between the local and applied strain rates was $\dot{\varepsilon}_{\text {loc }} \mid \dot{\varepsilon}_{a}=5$. It is clearly seen in Fig. 5a that the embryo band is initiated on the lateral surface of the specimen $(t=49.3 \mathrm{~s})$ and then, during its subsequent development, it acquires a wedge

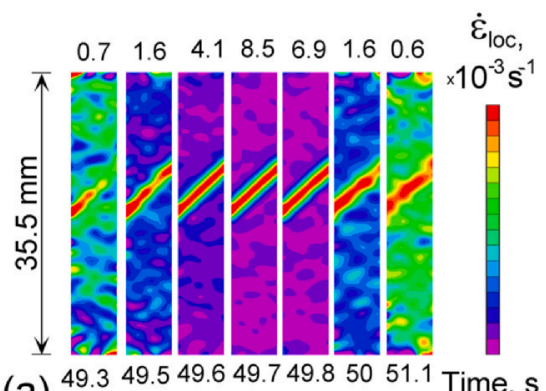

(a) 49.349 .549 .649 .749 .85051 .1 Time, s

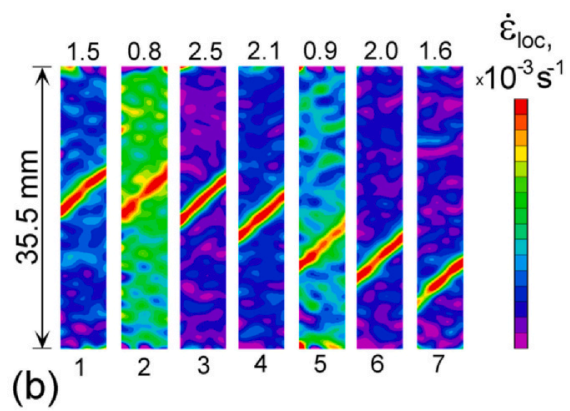

Frame Number

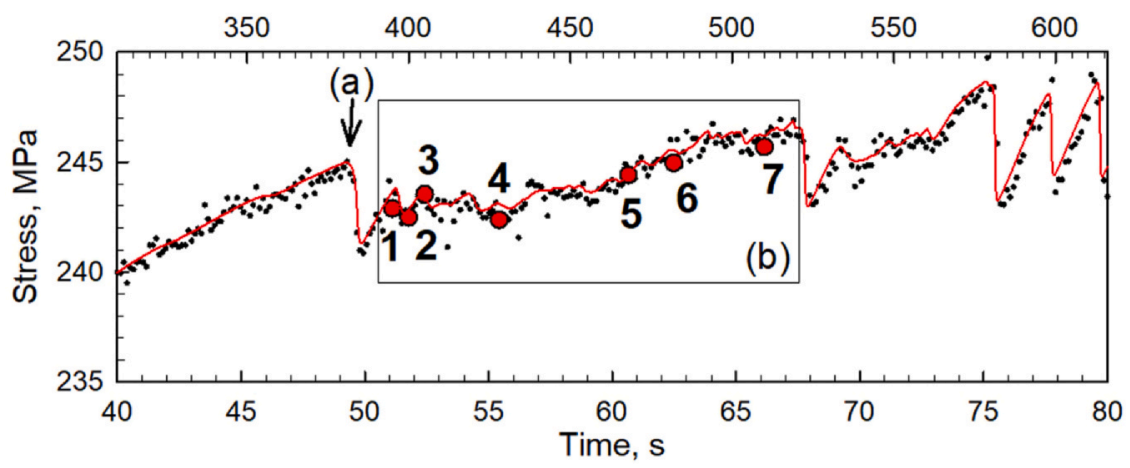

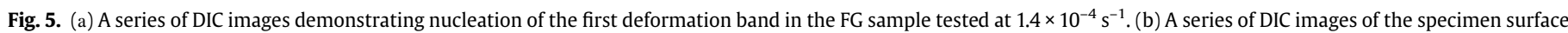
at the instants indicated in the bottom plot. 

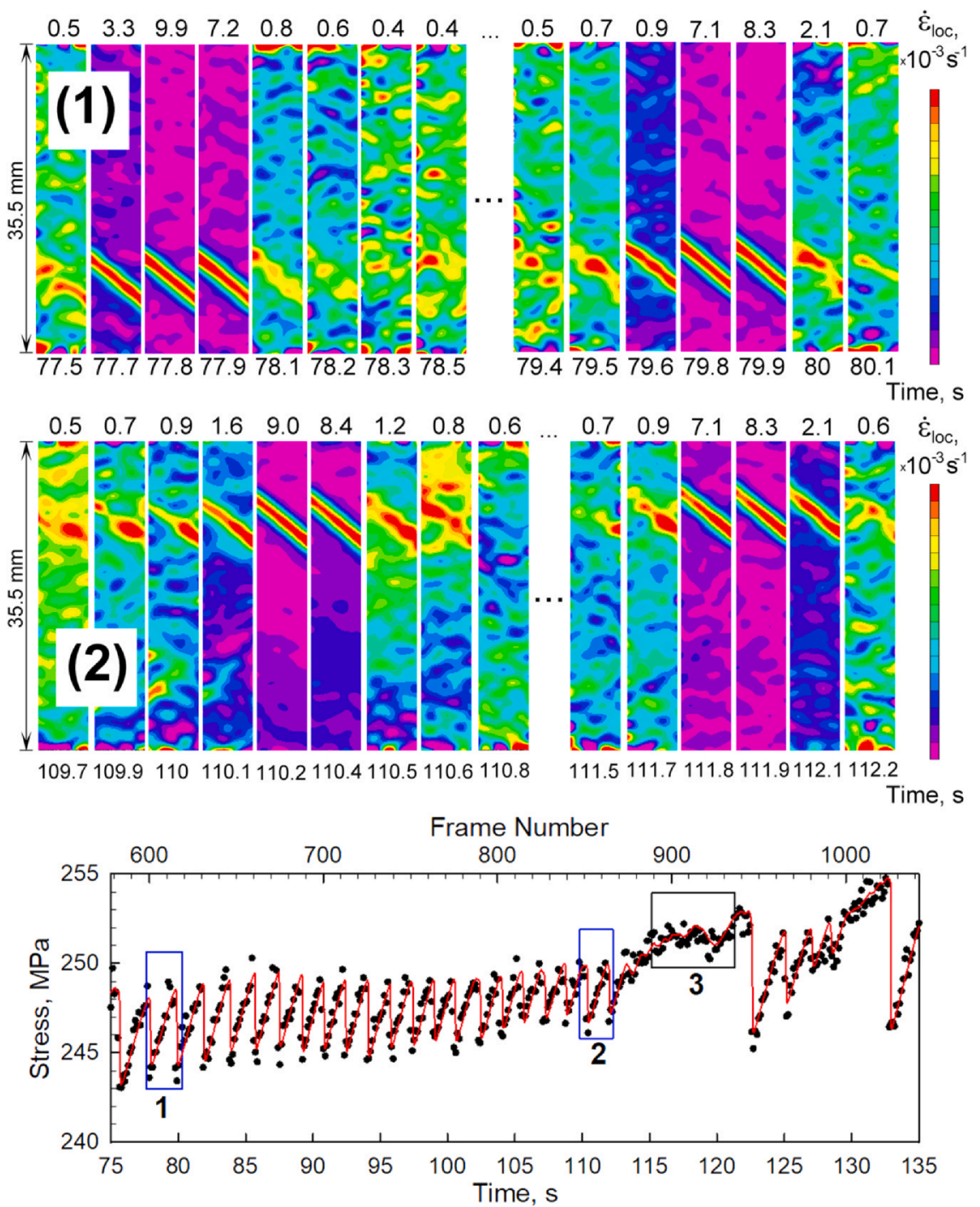

Fig. 6. An example of the hopping propagation of a PLC band of type B in the FG sample at the early deformation stage. $\dot{\varepsilon}_{a}=1.4 \times 10^{-4} \mathrm{~s}^{-1}$.

shape, which indicates the manifestation of a hybrid of the two types of band development [23].

Fig. 5b shows the propagation of the PLC band at the early deformation stage. It should be noted that $\dot{\varepsilon}_{\text {loc }}$ can be an order of magnitude higher than the applied strain rate, $\dot{\varepsilon}_{a}$ (frames $1,3,4,6$ and 7). "Healing" (frames 2 and 5) and re-nucleation (frames 3 and 6 ) of the band do not cause a large stress drop. This behavior is observed only at the beginning of the deformation curve after the first stress drop. It can be suggested that the strain heterogeneity at the early stage of deformation is insufficient for the implementation of a clearly expressed instability of type $B$.

When the time reaches about $75 \mathrm{~s}$, PLC bands of type B are observed (Fig. 6). Each new PLC band is nucleated near or at the peak of each stress drop, showing a hopping propagation. The PLC bands are initiated in the bottom gauge region of the specimen as shown for region 1 , and propagate in a hopping manner towards the upper edge of the specimen, as shown for region 2 in Fig. 6. This hopping propagation of deformation bands is observed before necking. The band-free phase for the FG material increases 2 times as compared to the CG material. Besides, a slight increase in the band lifetime by $0.1 \mathrm{~s}$ can be observed. This is probably due to an increase in the stress relaxation time because of increasing the density of grain boundaries after ECAP, the same can be found in
[39], when the stress relaxation time increased due to "precipitates that impede the correlation of dislocation dynamics". At the early stage of deformation, the ratio of the band-free phase to the lifetime of the band in the FG material comprises 4.3 , which is approximately equal to that in the CG alloy after a sufficiently large deformation. Similar to the CG state, the PLC bands are not found in region 3 (Fig. 6). The frames obtained at $t=\{109.9-110.1\}$ $\mathrm{s}$ and $t=\{111.5-111.7\}$ s confirm the growth into the volume at an angle with relation to the tensile axis during thickening in the tensile axis of the embryo band. The wedge-shape of the embryo bands is clearly seen on the frames at $t=110 \mathrm{~s}$ and $t=111.7 \mathrm{~s}$. The value of $\dot{\varepsilon}_{\text {loc }} \mid \dot{\varepsilon}_{a}$ for the embryo bands is about 6-7 in Fig. 6.

Fig. 7 illustrates the spatiotemporal behavior of the plastic flow of the SS material deformed at a strain rate of $1.4 \times 10^{-4} \mathrm{~s}^{-1}$. Continuous propagation of the diffuse band is observed all over the deformation curve between the yield point stress and the strength point (Fig. 7). It should be noted that this band is a weak strain heterogeneity, which starts forming at the yield point as a thick and loosely shaped area with $\dot{\varepsilon}_{\text {loc }}$ several times exceeding $\dot{\varepsilon}_{a}\left(\dot{\varepsilon}_{l o c} \mid \dot{\varepsilon}_{a} \approx 6\right.$ ) (Fig. 7). The band propagates through the gauge length. Similar results were observed for the same material (SS condition) at higher strain rates [27], when $\dot{\varepsilon}_{\text {loc }} \mid \dot{\varepsilon}_{a}$ was about 7, although the band in Ref. [27] did not pass through the entire gauge length. It can be concluded that a decrease 

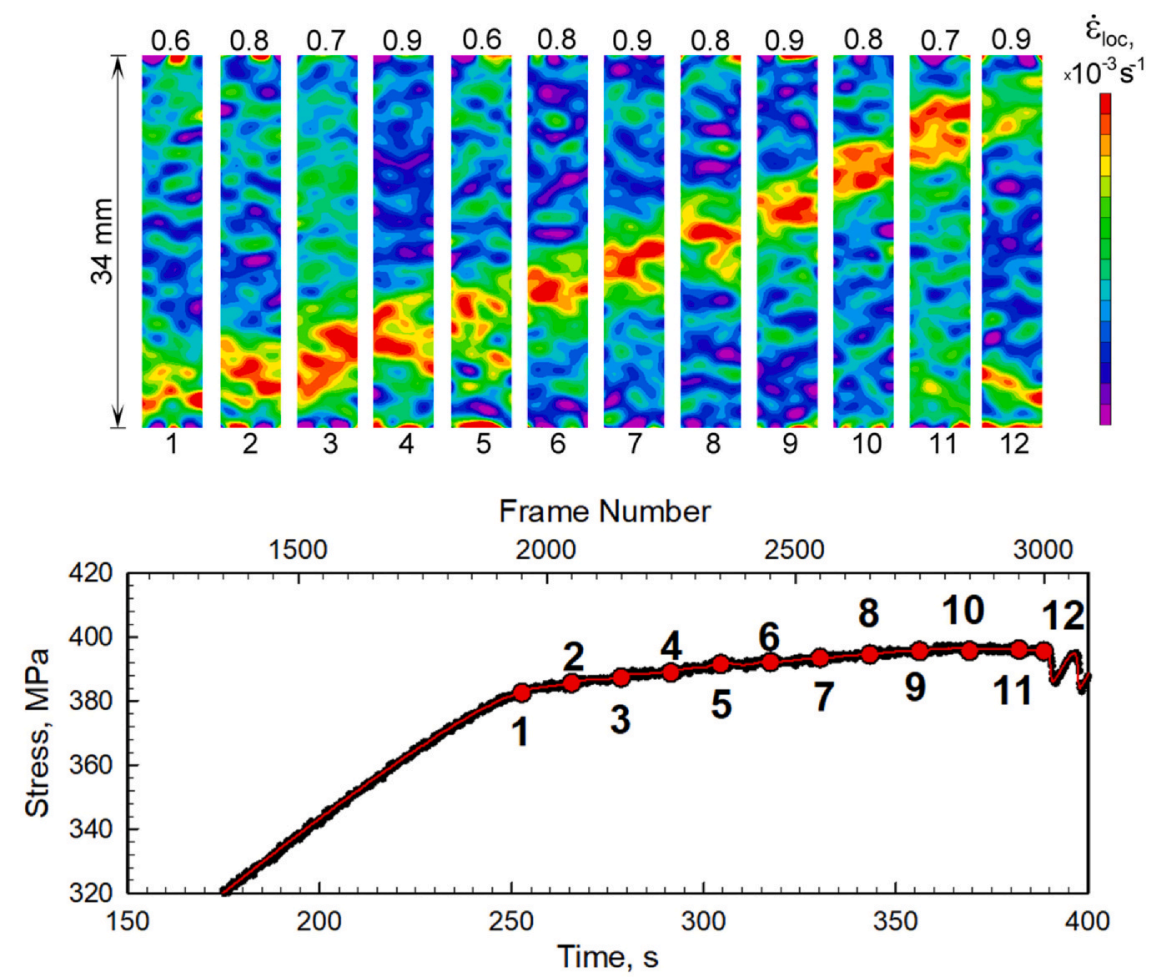

Fig. 7. A series of DIC images of the surface of the SS specimen tested at $1.4 \times 10^{-4} \mathrm{~s}^{-1}$ at the instants indicated in the bottom plot.

in both the maximum $\dot{\varepsilon}_{l o c}$ value and the strain rate is accompanied by an expansion in the band propagation.

Completed PLC bands appear during the necking stage, when the deformation curve is accompanied by regular stress oscillations (Fig. 8). Moreover, a series of distinct deformation bands (Fig. 8) instead of beats (the beat means that $\dot{\varepsilon}_{\text {loc }}$ never drops to the level of $\dot{\varepsilon}_{a}$ ) (cf. [27]) can be seen in the SS alloy. The maximum local strain rate at the peaks of the jumps (Frames 1 and 5 ) is an order of magnitude higher than the applied strain rate. A well-defined band with a ratio $\dot{\varepsilon}_{\text {loc }} / \dot{\varepsilon}_{a} \geq 50$ is formed during the stress drop phase (Frames 2 and 6 ). Thus, the intensity of strain localization within the bands is higher than for type A bands [27,28]. Next, the intensity of the bands reduces and exceeds the applied strain rate only by an order of magnitude (Frames 3 and 7). The displacement of the nucleation sites continues for some time after the onset of necking, in this case, the band forms a series of relay-race propagations typical for type B bands, ultimately concentrating in one cross-section [27].

\subsubsection{Band velocity}

Band velocity is an important parameter of the PLC bands kinematics. It should be noted that the methods for calculating the propagation velocity of bands of different types are different. The velocity of PLC bands of type A is determined as the speed of displacement of the areas position corresponding to the maximum local strain rate within the band [27]. A type B band has a short lifetime, corresponding to the duration of the stress drop phase, and a longer reloading time is required before the next band appears. The average velocity for type $B$ bands is determined by the hopping distance divided by the reloading time [26]. This so-called effective velocity of the hopping propagation is not a proper band velocity. Fig. 9 shows the change in the band velocity alongside with the true strain - true stress curves for the $\mathrm{Al}-3 \% \mathrm{Mg}$ alloy in different initial conditions. The band velocity in Fig. 9 was averaged. The band velocity was determined as the distance propagated by the band in a hopping manner in one direction, divided by the total propagation time.
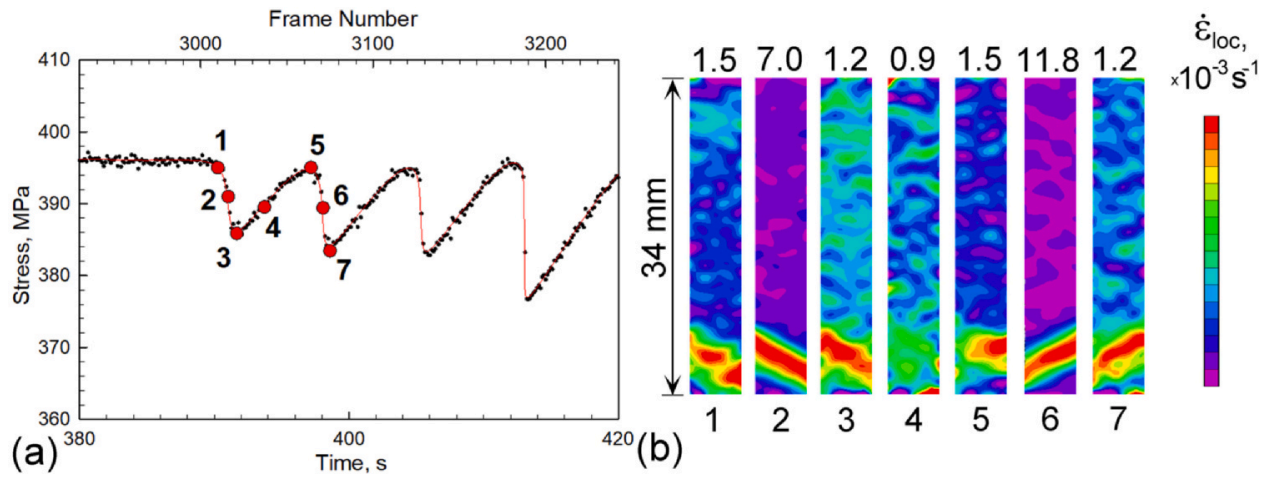

Fig. 8. Behavior of the stress oscillation during necking of the SS sample deformed at $1.4 \times 10^{-4} \mathrm{~s}^{-1}$. 

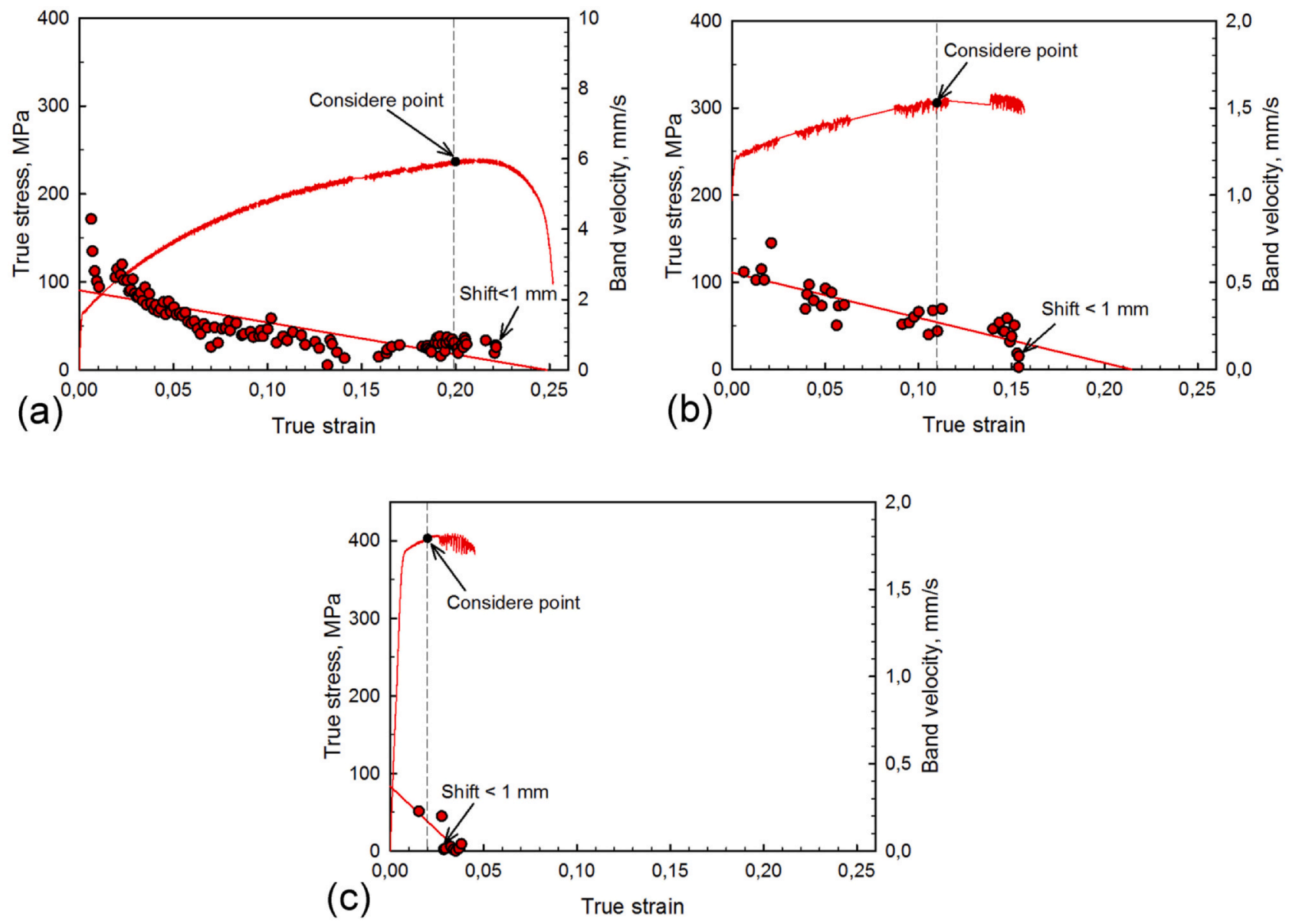

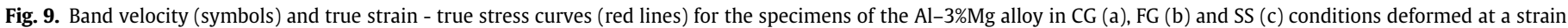
rate of $1.4 \times 10^{-4} \mathrm{~s}^{-1}$. (For interpretation of the references to color in this figure legend, the reader is referred to the web version of this article.)

The band velocity of the CG material deformed at $1.4 \times 10^{-4} \mathrm{~s}^{-1}$ gradually decreases in the range of true strains to 0.1 followed by stabilization at a nearly constant level at larger true strains (Fig. 9a). This suggests that the PLC band kinematics changes at different stages of work hardening. Similar behavior was observed in another study, which reported that the band motion became more and more difficult and the band velocity decreased as deformation proceeds $[34,40]$.

The FG material has only the decreasing dependence of the band velocity on the strain unlike the CG alloy (Fig. 9a and b). In addition, both changes in the microstructure and reduction of the strain rate (cf. [27]) lead to a decrease in the band velocity. Fig. 9 also shows that the band velocity does not vanish at the Considere strain, but propagates up to the maximum true stress. More precisely, the band can still move over a distance of more $1 \mathrm{~mm}$ after reaching the Considere strain as suggested in previous papers $[27,28]$.

\subsubsection{Nucleation and subsequent development of the PLC band at a} high strain rate

It is known that the manifestation feature of the PLC instability strongly depends on the strain rates. High strain rates are reported [20-22] to be associated with type A bands, whereas intermediate strain rates are characteristic for type B bands. Nevertheless, there is no clear understanding of the effect of the strain rate on the process of nucleation and subsequent development of the PLC band. This section presents an attempt to identify this influence. The effect of the microstructure on the high-speed behavior corresponding to the continuous propagation of the bands was considered in the previous work [27], however, no attention was paid to the nucleation and subsequent development of the PLC band at a high strain rate. For this purpose, an additional series of DIC images is presented below.

The nucleation of deformation bands of the $\mathrm{Al}-3 \% \mathrm{Mg}$ alloy in two (CG and FG) conditions tested at a high $\left(5 \times 10^{-3} \mathrm{~s}^{-1}\right)$ strain rate corresponding to the type A PLC bands is shown in Fig. 10. As clearly seen in Fig. 10, the embryo bands are arising on the lateral surface and thickening in the tensile direction during growth into the volume at an angle with relation to the tensile axis. The presence of wedge-shaped bands during this growth phase is characteristic for both conditions of the alloy. Thus, it becomes clear that the scenarios of the band development do not depend on the microstructure. In addition, studies of the nucleation and subsequent development of the PLC band in only one plane of the specimen surfaces allow us to conclude that the scenarios of the band development are not associated with different types of PLC bands (or strain rates). Whereas, it is necessary to conduct additional studies of the behavior of PLC bands on two orthogonal specimen surfaces to reveal the dependence of the band development on the strain rate.

\subsection{Effect of strain rate on the mechanism of nucleation and subsequent development of the PLC band}

As noted above, two limit types and one mixed type of the band development have been described in the literature [23]. These mechanisms are sketched in Fig. 11. Directions of embryo growth are indicated by the arrows. It should be noted that the first mechanism is associated with a band, which can have its ending width at nucleation, and then grow along its longitude direction (see Fig. 11a). The second mechanism is associated with the nucleation of a narrow 


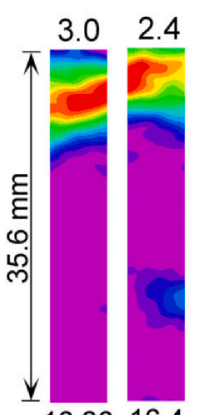

(a)
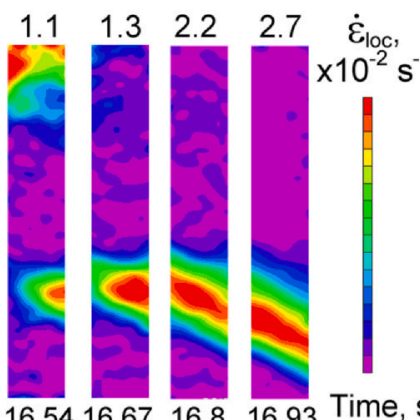

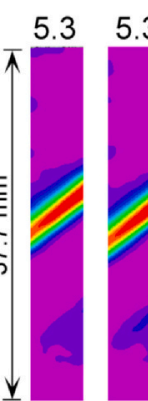

(b)
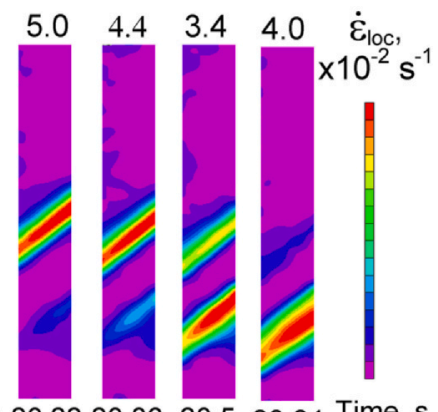

19.9420 .0820 .2220 .3620 .520 .64 Time, s

Fig. 10. A series of DIC images demonstrating the nucleation of a deformation band in the CG (a) and in the FG (b) samples tested at $5 \times 10^{-3} \mathrm{~s}^{-1}$.

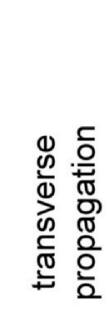

(a)
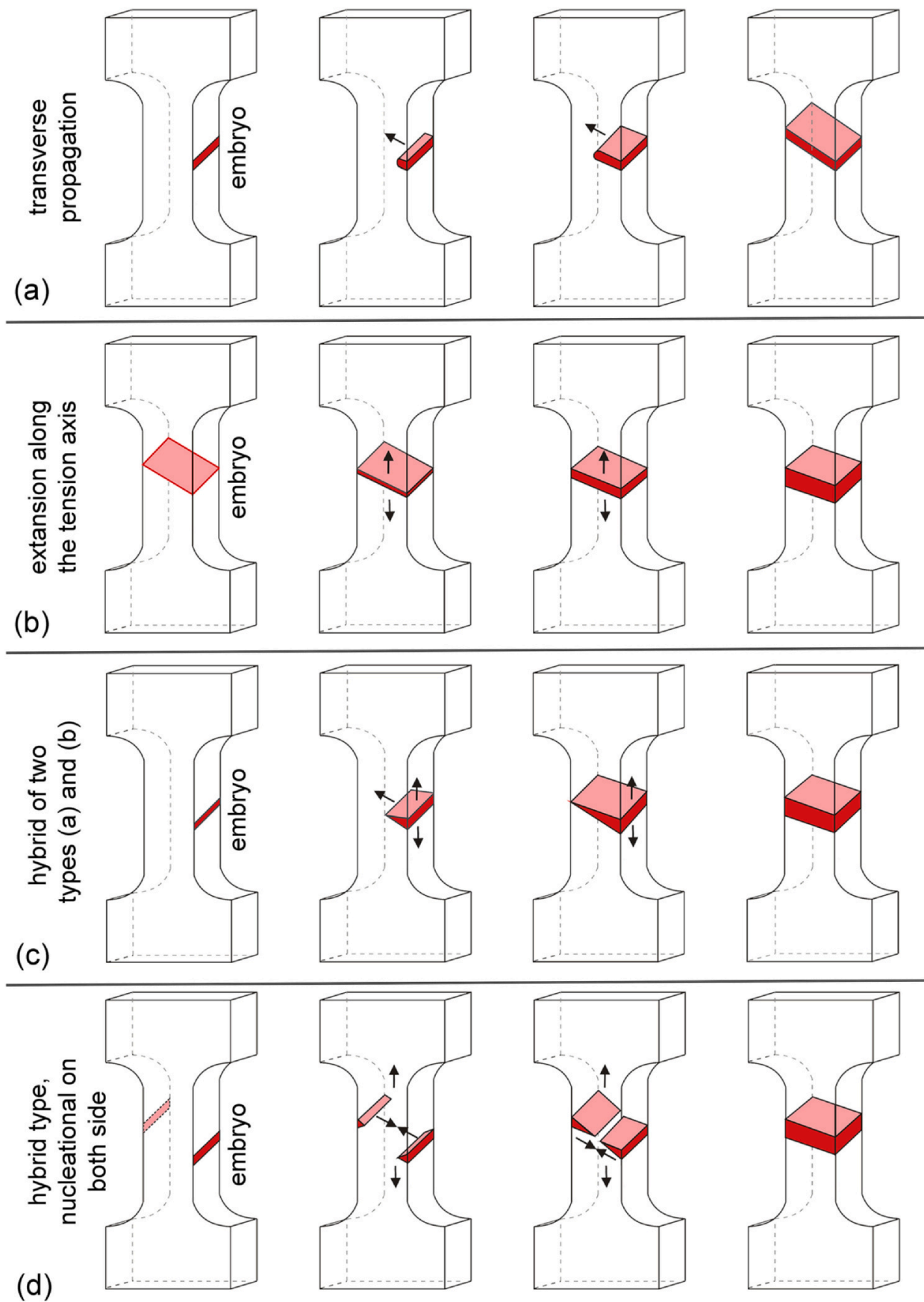

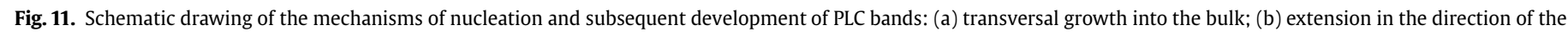
specimen axis; (c) a hybrid of the two types (a) and (b); (d) a hybrid of the two types with nucleation on both sides. 


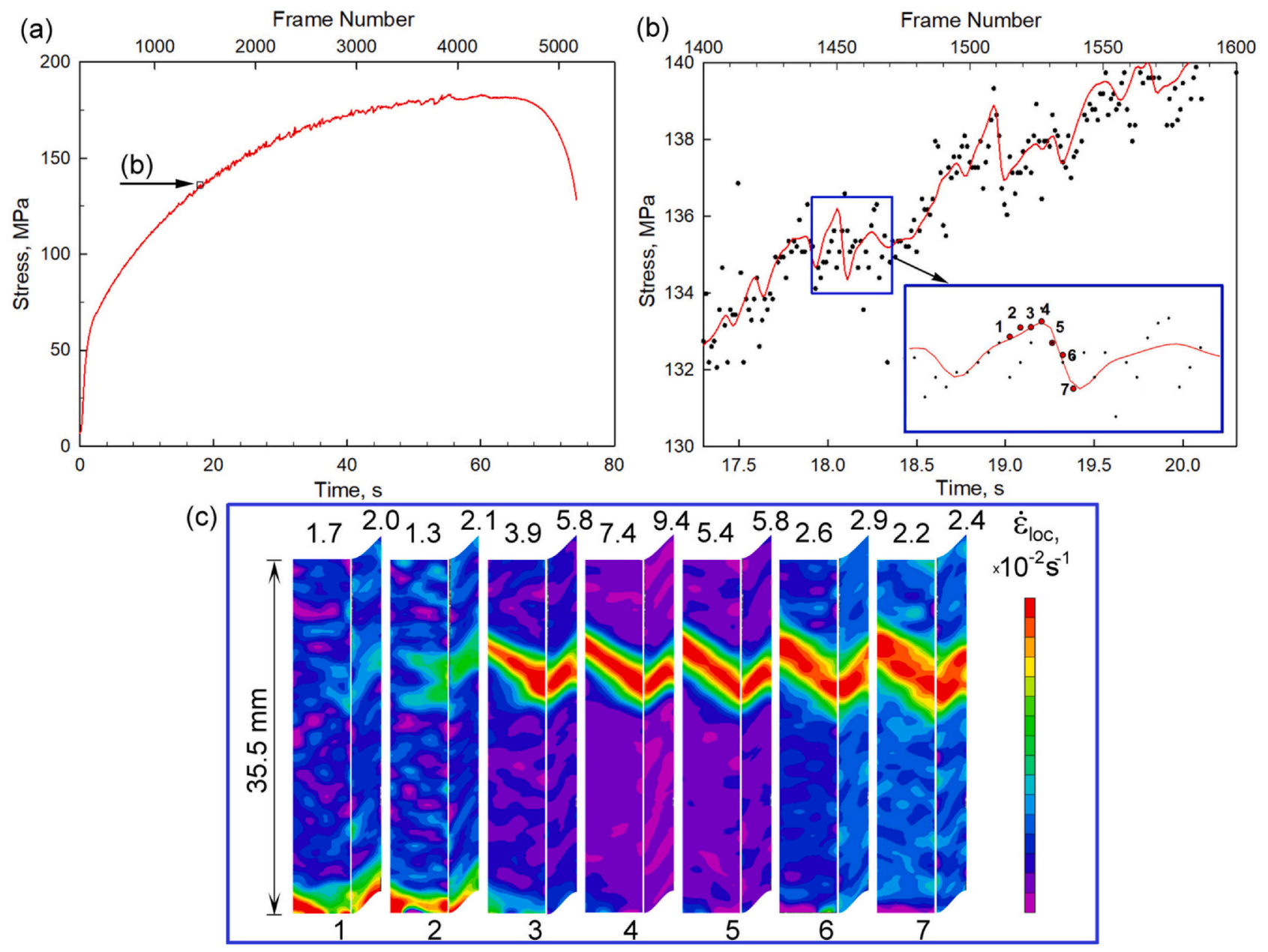

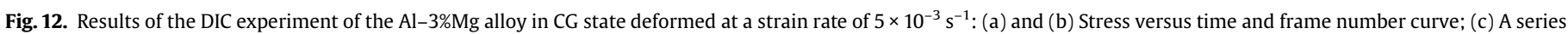
of DIC images of two specimen surfaces at the instants indicated in Fig. 12b.

band and subsequent expansion in the direction of the tension axis to develop a complete band (Fig. 11b). The mixed scenario considers the occurrence of an embryo on the lateral surface of the specimen, followed by its thickening in the tensile direction during growth into the volume at an angle with relation to the tensile axis. Herewith the embryo has a wedge shape during its growth as sketched in Fig. 11c.

However, Chihab et al. [23] have not verified their hypotheses due to the lack of direct strain measurements in their experiments. The results of high-speed filming, which suggest a possibility of the mixed scenario of the PLC band nucleation, were presented later [8-11,38,41].

In our study, the DIC experiment simultaneously on two orthogonal specimen surfaces was additionally carried out to confirm the possible mechanisms of the PLC band nucleation (Figs. 12 and 13). The presented results of the DIC analysis testify that the embryo band develops from the one edge to the other of the sample and acquires the shape of a wedge during motion, which then relaxes in the completed deformation band. Thus, the mixed scenario was obtained at high (type A; see Fig. 12) and intermediate (type B; not shown here) strain rates. In Ref. [42], a special case was described, when one or several grains along the shear direction can be activated quasi-simultaneously, which results in an active front across the entire width of the specimen. Feng et al. [43] noted the case when two type B bands nucleate at both edges of a specimen shoulder and propagate parallel to each other in opposite directions. A scheme illustrating the hybrid mechanism with the PLC band nucleation on both edges of the specimen is shown in Fig. 11d. Current experimental results also show that a hybrid of the two types with the band initiation process in two regions and subsequent development of the PLC band in opposite directions is also conceivable at the intermediate strain rate corresponding to type B bands (Fig. 13).

Fig. 14a and $b$ shows the evolution of local strain rate distributions in tensile testing during nucleation of type A and type B bands, respectively. To estimate the embryo band thickness, the distance between the two nearest minima of the local strain rate profile was determined. The thickness of the embryo band increased as it grew rapidly. The observation that the simultaneous formation of type- $A$ bands in both the transverse and longitudinal directions occurs after the nucleation phase is consistent with the results of other authors $[38,43]$. However, another feature was identified; namely, the thickening of the type A bands in the tensile direction is more significant compared with the change in the thickness of the type $B$ bands (Fig. 14). It can be assumed that the higher the strain rate, the lower the relaxation of internal stresses due to dynamic recovery. Thus, the level of local overstresses controls the formation velocity of the deformation band, as noted earlier in Refs. [38,41]. Thus, the results obtained suggest that the nucleation of deformation bands always occurs according to a mixed mechanism, regardless of the structure, in which the thickening of the embryo slows down with a decrease in the strain rate. 

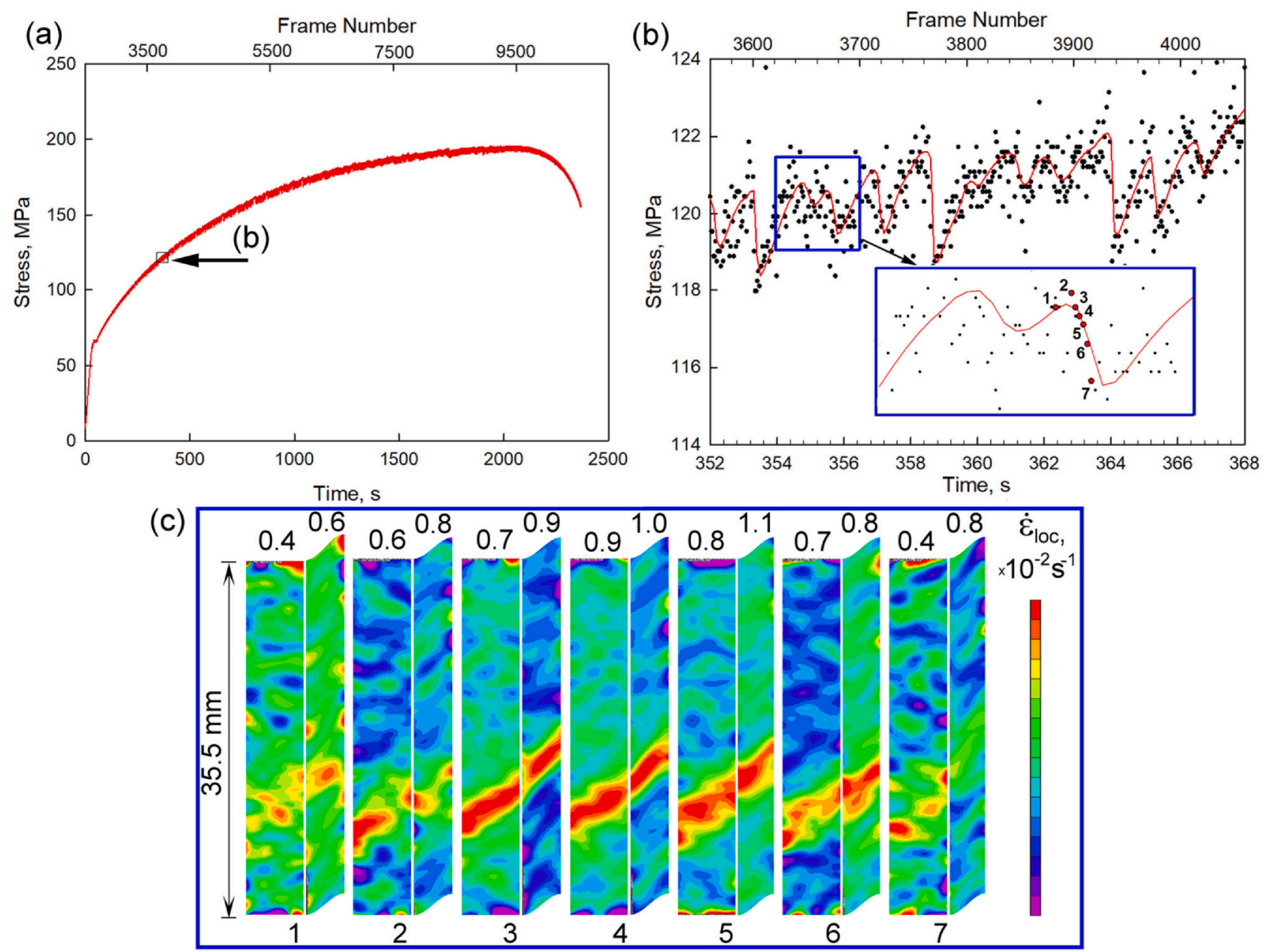

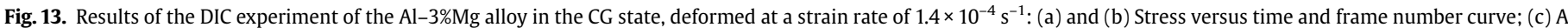
series of DIC images of two specimen surfaces at the instants indicated in Fig. 13b.
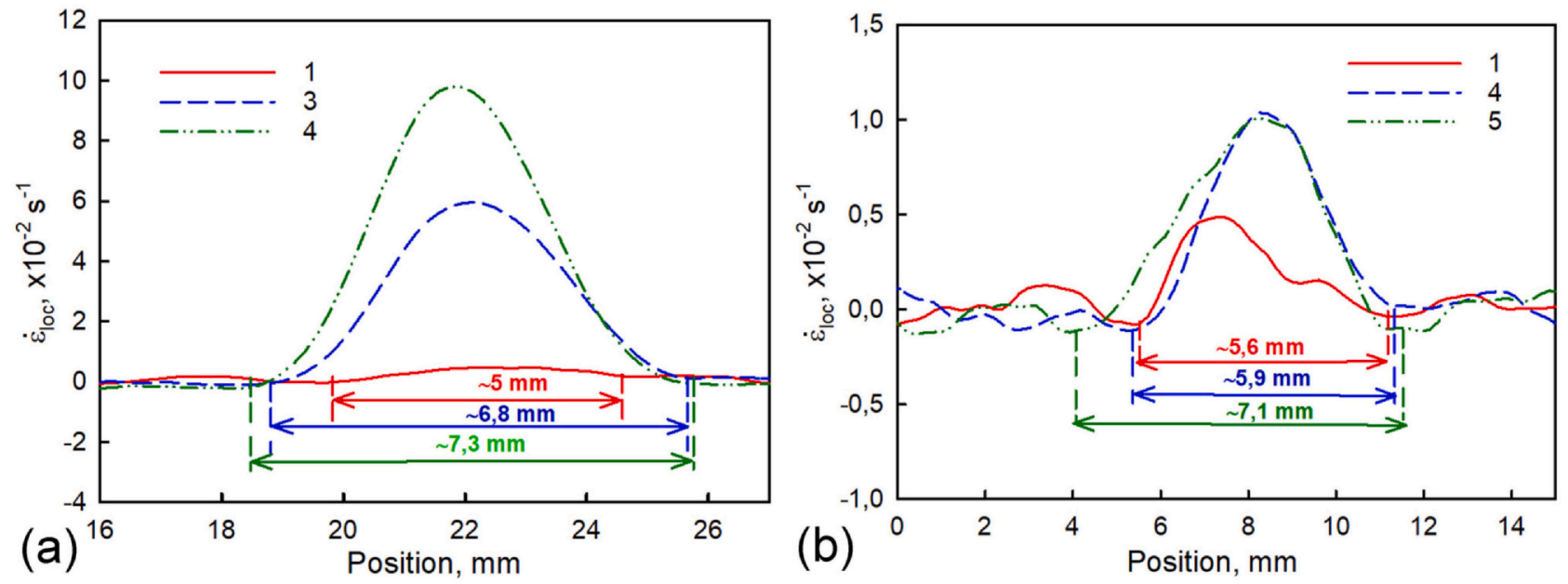

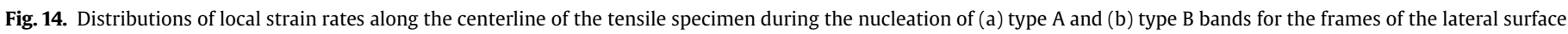
of the specimen from Figs. $12 \mathrm{c}$ and $13 \mathrm{c}$, respectively. The arrows indicate the thickness value of the embryo band.

\section{Conclusions}

1. The $\mathrm{Al}-3 \% \mathrm{Mg}$ alloy in the CG and FG states demonstrates the kinematics of the PLC bands corresponding to the hopping propagation and type B stress serrations in spite of the tendency to the type $C$ serration stress for the FG states. Cold rolling of the FG samples (SS state) leads to repression of stress serrations until the onset of necking. In the SS samples, the propagation of diffuse bands can be observed.

2. The nucleation of deformation bands in the $\mathrm{Al}-3 \% \mathrm{Mg}$ alloy can be considered as a hybrid of two types of band development. Namely, the formation of an embryo on the lateral specimen 
surface and its thickening in the tensile direction during growth into the volume at an angle with relation to the tensile axis, so that the embryo band acquires the shape of a wedge during this growth phase. The scenario of the PLC band nucleation is independent of both the microstructure and the stress serration type (or strain rate). Nonetheless, thickening of the embryo band slows down with a decrease in the strain rate. The ratio of the local strain rate to the applied one, $\dot{\varepsilon}_{\text {loc }} / \dot{\varepsilon}_{a}$, required for the PLC band nucleation (i.e. the appearance of the embryo bands) increases with straining.

3. The grain refinement leads to an increase in both the band lifetime and the band-free phase. The ratio of the band-free phase to the band lifetime in the FG alloy is higher than in the CG alloy.

4. The dependences of the band velocity and the serration amplitude on strain indicate the absence of the saturation stage in the FG state of the $\mathrm{Al}-3 \% \mathrm{Mg}$ alloy.

\section{CRediT authorship contribution statement}

D. Yuzbekova: Conceptualization, Methodology, Investigation, Analysis, Writing - Reviewing and Editing. A. Mogucheva: Validation, Conceptualization, Analysis, Writing - Reviewing and Editing, Original draft preparation. Yu. Borisova: Investigation, Analysis; Writing. R. Kaibyshev: Conceptualization, Discus of results.

\section{Declaration of Competing Interest}

The authors declare that they have no known competing financial interests or personal relationships that could have appeared to influence the work reported in this paper.

\section{Acknowledgments}

The main results were obtained by using the equipment of the Joint Research Center, "Technology and Materials", Belgorod State University.

\section{References}

[1] A. Portevin, F. LeChatelier, Sur un phenomene observe lors de l'essai de traction d'alliages en cours de transformation, Compt. Rend. Acad. Sci. Paris 176 (1923) 507-510.

[2] A. Shibkov, M. Gasanov, M. Zheltov, A. Zolotov, V. Ivolgin, Intermittent plasticity associated with the spatio-temporal dynamics of deformation bands during creep tests in an AlMg polycrystal, Int. J. Plast. 86 (2016) 37-55, https://doi.org/ 10.1016/j.ijplas.2016.07.014

[3] P.Y. Manach, S. Thuillier, J.W. Yoon, J. Coër, H. Laurent, Kinematics of Portevin-Le Chatelier bands in simple shear, Int. J. Plast. 58 (2014) 66-83, https://doi.org/10. 1016/j.ijplas.2014.02.005

[4] M.J. Kim, M.G. Lee, K. Hariharan, S.T. Hong, I.S. Choi, D. Kim, K.H. Oh, H.N. Han, Electric current-assisted deformation behavior of $\mathrm{Al}-\mathrm{Mg}-\mathrm{Si}$ alloy under uniaxial tension, Int. J. Plast. 94 (2017) 148-170, https://doi.org/10.1016/j.ijplas.2016.09.010

[5] J. Kreyca, E. Kozeschnik, State parameter-based constitutive modelling of stress strain curves in Al-Mg solid solutions, Int. J. Plast. 103 (2018) 67-80, https://doi. org/10.1016/j.ijplas.2018.01.001

[6] T. Brynk, K.J. Kurzydlowski, Coupling of ultrasounds with the Portevin-Le Chatelier serrations as observed in aluminium-magnesium alloy in mini-samples tensile tests, Scr. Mater. 174 (2020) 14-18, https://doi.org/10.1016/j. scriptamat.2019.08.024

[7] B. Klusemann, G. Fischer, T. Böhlke, B. Svendsen, Thermomechanical characterization of Portevin-Le Châtelier bands in AlMg3 (AA5754) and modeling based on a modified Estrin-McCormick approach, Int. J. Plast. 67 (2015) 192-216, https://doi.org/10.1016/j.ijplas.2014.10.011

[8] A.A. Shibkov, M.A. Lebyodkin, T.A. Lebedkina, M.F. Gasanov, A.E. Zolotov, A.A. Denisov, Millisecond dynamics of deformation bands during discontinuous creep in an AlMg polycrystal, Phys. Rev. E 102 (2020) 043003, https://doi.org/10. 1103/PhysRevE.102.043003

[9] A.A. Shibkov, M.A. Zheltov, M.F. Gasanov, A.E. Zolotov, A.A. Denisov, M.A. Lebyodkin, Dynamics of deformation band formation investigated by highspeed techniques during creep in an AlMg alloy, Mater. Sci. Eng. A 772 (2020) 138777, https://doi.org/10.1016/j.msea.2019.138777

[10] A.A. Shibkov, M.A. Zheltov, M.F. Gasanov, A.E. Zolotov, A.A. Denisov, S.S. Kochegarov, Studying high-frequency acoustic emission during discontinuous creep in an aluminum-magnesium alloy, Tech. Phys. 65 (2020) 1622-1629, https://doi.org/10.1134/S1063784220100199

[11] A.A. Shibkov, M.F. Gasanov, A.E. Zolotov, A.A. Denisov, S.S. Kochegarov, R.Y. Koltsov, High-speed in situ study of the correlation between the deformation bands formation and acoustic response in Al-Mg alloy, Crystallogr. Rep. 65 (2020) 546-553, https://doi.org/10.1134/S1063774520040185

[12] P.G. McCormick, Theory of flow localization due to dynamic strain ageing, Acta Met. 36 (1988) 3061-3067.

[13] N. Chibane, H. Ait-Amokhtar, C. Fressengeas, On the strain rate dependence of the critical strain for plastic instabilities in Al-Mg alloys, Scr. Mater. 130 (2017) 252-255, https://doi.org/10.1016/j.scriptamat.2016.11.037

[14] D. Delpueyo, X. Balandraud, M. Grédiac, Calorimetric signature of the Portevin-Le Chatelier effect in an aluminum alloy from infrared thermography measurements and heat source reconstruction, Mater. Sci. Eng. A 651 (2016) 135-145, https://doi.org/10.1016/j.msea.2015.10.053

[15] X. Nie, H. Zhang, H. Zhu, Z. Hu, Y. Qi, X. Zeng, On the role of Zr content into Portevin-Le Chatelier (PLC) effect of selective laser melted high strength Al-Cu-Mg-Mn alloy, Mater. Lett. 248 (2019) 5-7, https://doi.org/10.1016/j. matlet.2019.03.112

[16] P. Rodriguez, Serrated plastic flow, Bull. Mater. Sci. 6 (1984) 653-663, https://doi. org/10.1007/BF02743993

[17] P. Zhou, Y. Song, L. Hua, J. Lu, J. Zhang, F. Wang, Mechanical behavior and deformation mechanism of 7075 aluminum alloy under solution induced dynamic strain aging, Mater. Sci. Eng. A 759 (2019) 498-505, https://doi.org/10.1016/j. msea.2019.05.071

[18] M. Lebyodkin, L. Dunin-barkowskii, Y. Breâchet, Y. Estrin, L.P. Kubin, Spatiotemporal dynamics of the PortevinLe Chatelier effect: experiment and modeling, Acta Mater. 48 (2000) 2529-2541, https://doi.org/10.1016/S1359-6454(00) 00067-7

[19] J. Brecht, S.Y. Chen, X. Xie, Y. Ren, J.W. Qiao, P.K. Liaw, S.J. Zinkle, Towards a greater understanding of serrated flows in an Al-containing high-entropy-based alloy, Int. J. Plast. 115 (2019) 71-92, https://doi.org/10.1016/j.ijplas.2018.11.011

[20] H. Jiang, Q. Zhang, X. Chen, Z. Chen, Z. Jiang, X. Wu, J. Fan, Three types of PortevineLe Chatelier effects: experiment and modeling, Acta Mater. 55 (2007) 2219-2228, https://doi.org/10.1016/j.actamat.2006.10.029

[21] R. Sarmah, G. Ananthakrishna, Correlation between band propagation property and the nature of serrations in the Portevin-Le Chatelier effect, Acta Mater. 91 (2015) 192-201, https://doi.org/10.1016/j.actamat.2015.03.027

[22] A. Mogucheva, D. Yuzbekova, R. Kaibyshev, T. Lebedkina, M. Lebyodkin, Effect of grain refinement on jerky flow in an Al-Mg-Sc alloy, Metall. Mater. Trans. 47 (2016) 2093-2106, https://doi.org/10.1007/s11661-016-3381-2

[23] K. Chihab, Y. Estrin, L.P. Kubin, J. Vergnol, The kinetics of the Portevin-Le Chatelier effect in an Al-5at\%Mg alloy, Scr. Metall. 21 (1987) 203-208, https:// doi.org/10.1016/0036-9748(87)90435-2

[24] U.F. Kocks, Progress in Materials Science, Chalmers Anniversary, Pergamon Press, Oxford, 1981, p. 225.

[25] W. Tong, H. Tao, N. Zhang, L.G. Hector Jr., Time-resolved strain mapping measurements of individual Portevin-Le Chatelier deformation bands, Scr. Mater. 53 (2005) 87-92, https://doi.org/10.1016/j.scriptamat.2005.03.020

[26] T.A. Lebedkina, M.A. Lebyodkin, T.T. Lamark, M. Janeček, Y. Estrin, Effect of equal channel angular pressing on the PortevineLe Chatelier effect in an Al3Mg alloy, Mater. Sci. Eng. 615 (2014) 7-13, https://doi.org/10.1016/j.msea.2014.07.064

[27] D. Yuzbekova, A. Mogucheva, D. Zhemchuzhnikova, T. Lebedkina, M. Lebyodkin, R. Kaibyshev, Effect of microstructure on continuous propagation of the Portevin-Le Chatelier deformation bands, Portevin-Le Chatelier deformation bands, Int. J. Plast. 96 (2017) 210-226, https://doi.org/10.1016/j.ijplas.2017.05.004

[28] D. Zhemchuzhnikova, M. Lebyodkin, D. Yuzbekova, T. Lebedkina, A. Mogucheva, R. Kaibyshev, Interrelation between the Portevin Le-Chatelier effect and necking in AlMg alloys, Int. J. Plast. 110 (2018) 95-109, https://doi.org/10.1016/j.ijplas. 2018.06.012

[29] S. Zhao, C. Meng, F. Mao, W. Hu, G. Gottstein, Influence of severe plastic deformation on dynamic strain aging of ultrafine grained Al-Mg alloys, Acta Mater. 76 (2014) 54-67, https://doi.org/10.1016/j.actamat.2014.05.004

[30] A. Sarkar, P. Barat, P. Mukherjee, Investigation of PortevineLe Chatelier effect in Al-2.5 pct Mg alloy with different microstructure, Metall. Mater. Trans. A 44 (2013) 2604-2612, https://doi.org/10.1007/s11661-013-1630-1

[31] R. Kapoor, C. Gupta, G. Sharma, J.K. Chakravartty, Deformation behavior of $\mathrm{Al}-1.5 \mathrm{Mg}$ processed using the equal channel angular pressing technique, Scr. Mater. 53 (2005) 1389-1393, https://doi.org/10.1016/j.scriptamat.2005.08.026

[32] M.A. Lebyodkin, D.A. Zhemchuzhnikova, T.A. Lebedkina, E.C. Aifantis, Kinematics of formation and cessation of type B deformation bands during the Portevin-Le Chatelier effect in an AlMg alloy, Results Phys. 12 (2019) 867-869, https://doi. org/10.1016/j.rinp.2018.12.067

[33] Y.L. Cai, S.L. Yang, Y.H. Wang, S.H. Fu, Q.C. Zhang, Characterization of the deformation behaviors associated with the serrated flow of a 5456 Al-based alloy using two orthogonal digital image correlation systems, Mater. Sci. Eng. A 664 (2016) 155-164, https://doi.org/10.1016/j.msea.2016.04.003

[34] H. Ait-Amokhtar, C. Fressengeas, Crossover from continuous to discontinuous propagation in the PortevineLe Chatelier effect, Acta Mater. 58 (2010) 1342-1349, https://doi.org/10.1016/j.actamat.2009.10.038

[35] M. Jobba, R.K. Mishra, M. Niewczas, Flow stress and work-hardening behaviour of Al-Mg binary alloys, Int. J. Plast. 65 (2015) 43-60, https://doi.org/10.1016/j. ijplas.2014.08.0062015

[36] Y. Estrin, L.P. Kubin, Collective dislocation behavior in dilute alloys, J. Mech. Behav. Mater. 2 (1990) 255-292. 
[37] M. Mehenni, H. Ait-Amokhtar, C. Fressengeas, Spatiotemporal correlations in the Portevin-Le Chatelier band dynamics during the type B-type $C$ transition, Mater. Sci. Eng. A 756 (2019) 313-318, https://doi.org/10.1016/j.msea.2019.04.036

[38] L. Casarotto, H. Dierke, R. Tutscha, H. Neuhäuser, On nucleation and propagation of PLC bands in an Al-3Mg alloy, Mater. Sci. Eng. A 527 (2009) 132-140, https:// doi.org/10.1016/j.msea.2009.07.043

[39] N.P. Kobelev, M.A. Lebyodkin, T.A. Lebedkina, Role of self-organization of dislocations in the onset and kinetics of macroscopic plastic instability, Metall. Mater. Trans. A 48 (2017) 965-974, https://doi.org/10.1007/s11661016-3912-X

[40] M. Mehenni, H. Ait-Amokhtar, C. Fressengeas, Spatiotemporal correlations in the Portevin-Le Chatelier band dynamics during the type B - type C transition,
Mater. Sci. Eng. A 756 (2019) 313-318, https://doi.org/10.1016/j.msea.2019.04. 036

[41] M.M. Krishtal, A.K. Khrustalev, A.V. Volkov, S.A. Borodin, Nucleation and growth of macrofluctuations of plastic strain with discontinuous yield and luders deformation: results of high-speed video filming, Dokl. Phys. 54 (5) (2009) 225-229, https://doi.org/10.1134/S1028335809050024

[42] Wei Tong, Hong Tao, Nian Zhang, Louis G. Hector Jr., Time-resolved strain mapping measurements of individual Portevin-Le Chatelier deformation bands, Scr. Mater. 53 (2005) 87-92, https://doi.org/10.1016/j.scriptamat.2005.03.020

[43] X. Feng, G. Fischer, R. Zielke, B. Svendsen, W. Tillmann, Investigation of PLC band nucleation in AA5754, Mater. Sci. Eng. A 539 (2012) 205-210, https://doi.org/10. 1016/j.msea.2012.01.082 